\title{
Evaluation of an information campaign about working safely with carcinogenic substances
}

\author{
Ingrid P.P. Moonen ${ }^{\text {a }}$, Gerrit A.J. van der Rijt ${ }^{\text {a.* }}$, \\ Karel F.C.J. van Koppen ${ }^{b}$, \\ Joost W.J. van der Gulden ${ }^{c}$ \\ "Deparment of Communication Science, University of Nijmegen. Nijmegen. The Netherlands \\ "Dutch Cancer Socieiy, Amsterdam. The Netherlands \\ 'Department of Occupational Medicine. University of Nijmegen. P.O. Box 9101.6500 HB Nijmegen. \\ The Netherlands
}

\begin{abstract}
An information campaign, organised in the Netherlands to foster safer working conditions for those who find themselves exposed to carcinogenic substances, has been evaluated. Posters, leaflets, and booklets had been distributed to those who are liable to run a risk while at work, managers as well as workmen. To assess the impact and the effects of the campaign, a panel study was carried out among those employees who actually handle carcinogenic substances. A random sample of this target group $(N=548$ ) was interviewed by telephone a short while before the start of the campaign (pretest) and then again three months after its inception (posttest). In addition, a similar sample from the target group $(N=550)$ was approached for a positest only, to control for potential measurement effects. The reach and respondents' opinion of the campaign materials, was charted as well. By means of covariance and loglinear analysis an inventory was made of the resulting changes in knowledge, attitude, behavioural intentions and interpersonal communication concerning work involving carcinogens.

It was found that people who had had the opportunity to study the information ended up being more alive to the risks of working with carcinogenic substances and were better able to take preventive action. A further positive effect is that the campaign appears to have encouraged people to communicate on the subject with colleagues, with management and with others (including the occupational health officer).
\end{abstract}

\section{Introduction}

At this moment an information campaign is in progress in the various countries of the EU using the motto "Europe against cancer". The object of this campaign is to reduce the

* Corresponding author. 
expected mortality from cancer during the nineties by $15 \%$. As part of it a "European Cancer Code" is being drawn up. This Code summarizes in ten advices what everyone should do to prevent cancer and to detect the disease in an eariy stage. One of the advices is: "to follow safety guidelines at work", in order to reduce occupational cancer. In the Netherlands a separate campaign was organised, named "Work wisely", involving this specific advice. This campaign is directed towards all employers and employees who may work with carcinogenic substances. Its message is: "know the substances, know the risks, know the precautions and act accordingly'. The campaign's aim is to further awareness of the risks and the mutual communication about these matters between those involved, e.g., workers, principals, employers and occupational health officers. Promotion of interpersonal communication can make campaigns more effective especially in realising behaviour change (see among others: Rogers, 1983; Alcalay, 1983; Flay, 1987). "Work wisely"' is coordinated and funded by the Dutch Cancer Society in cocperation with the Ministry of Labour and Social Affairs.

The message of the campaign "Work wisely" is spread by means of posters, leaflets and booklets. The poster carries a short message: "Carcinogenic substances? Protection essential!'. The leaflet contains the same message, and also where to obtain information in case of doubt. One advice is: "read the product information on the labels and ask your principals, employer, occupational health officer or trade union for further information"'. It is stressed that the employer has the legal duty to inform his employees on this matter. Safety precautions which can be taken are suggested. The booklet ( 47 pages) contains more extensive information on the relationship between occupation and cancer risk, on the characteristics of carcinogenic substances, on (problems of) research into carcinogenic properties, on the extent of the risks to get cancer when one has been exposed, on legislation, on exposure prevention and on how and where to get information. In addition, advices to decrease the risks and a list of known or suspected carcinogenic substances are offered in the booklet. The advices to consult relevant others is meant to stimulate interpersonal communication on the issue.

The information material is distributed through family doctors, chemist's shops and libraries. Furthermore, a large number of companies and institutions (including occupational health services) have been invited to order these materials. The campaign also brought about a lot of free publicity: newspapers, radio and television paid extensive attention to it.

It is not to be expected that a mass media campaign like "Work wisely" will of itself lead directly to lasting behaviour changes. More likely the effect will be that knowledge of the subject matter grows and that interest in it grows accordingly. In this way more attention to, and understanding of, the matter on which information is given, is realized: necessary steps in a process towards actual behaviour change (McGuire, 1981). Research has shown that campaigns which are helped by word-of-mouth dissemination are likely to lead to wider and more lasting behaviour change than campaigns as such (Richman and Urban, 1978; Van der Rijt, 1979; Alcalay, 1983; Rogers, 1983; Van der Rijt and Baan, 1984; Flay, 1987).

To achieve the intended behavioural changes with regard to working with carcinogenic substances, it is not enough that workers are willing to work safely. More than anything else they will need a certain amount of instruction and training in how to put this into practise. The management should also arrange for safe workplaces and methods, and make devices for personal protection available. Industrial hygienists, safety experts and occupa- 
tional health officers have to play their own parts in this process. One way to make it work is to get people to talk about the risks of exposure to carcinogenic substances.

In short, the research question of this study reads: to what extent has the campaign "Work wisely" led to changes in knowledge, attitude and behavioural intentions towards contact with carcinogenic substances on the worksite? Particular attention was paid to the campaign's influence on communication with colleagues, management and the occupational health officer. The employees were also asked to give their own comment on the campaign. Because the study took place some months after the start of the campaign it was only possible to establish the short-term effects.

\section{Research methods}

In order to establish the effects of the campaign, a quasi-experimental design was used including a measurement-control group. Because a real experimental design is often not feasible when evaluating mass media campaigns, this design seemed to be the best method as it comes nearest to a real experiment. Since in the nature of things nobody is excluded from receiving the campaign message, it is not possible to manipulate the experimental factor by creating both an experimental and a control group by means of random assignment. In the design chosen a random sample of people from the target group (those working in potentially risky occupations) were interviewed at two different times: shortly before (pretest) and three months after the start of the campaign (posttest). This is the panel group. At the first measurement time 747 people were interviewed for the panel group. Owing to panel drop out only $548(73 \%)$ could be interviewed for the second measurement. In addition a similar random sample of 550 people from the target group (the measurementcontrol group; was postrested only. This was done to find possible measurement effects caused by the pretest, in order to control these effects in further analyses. Effects of the campaign are assessed by comparing the answers of three subgroups of the pariel group: those who have been "directly informed", or "indirectly informed" by the campaign, versus those who are "non-informed". By controlling for the pretest scores and other included potentially confounding factors an approximation of an experimental matching procedure of both groups can be realised in the analysis.

Data were collected by means of brief telephonic interviews. All telephone calls were done by trained interviewers who were unaware of the underlying research questions. Study subjects were selected from amongst employees who worked in a risk sector ${ }^{\prime}$ for at least 24 hours a week. The response rate for the panel was $48 \%$ at the time of the pretest. The measurement-control group reached the same response rate. An outline of the research

' The risk sectors set by experts are: electricity-/gas-/ and water services, petroleum industry, waste disposal plants, road transport and huulage, building industry, chemical/pharmaceutical industry, garage business/service station, graphic industry, wholesale and distributive trade of chemical/pharmaceutical raw materials, woodpeserving industry, leather industry, machine works, engineering industry, furnishing/woodworking industry, rubber processing industry, ship building, cleaning services, textile industry, laundry/chemical cleaning. Moreover, the following professions were defined as riskful: chemist and chemist's assistant, nurse in an oncology ward, co-worker in a laboratory (medical research-worker) and (house-) painter. 
Table 1

Schematic outline of the research design

\begin{tabular}{|c|c|c|c|c|}
\hline & $\begin{array}{l}\text { (Pretest) } \\
21-28 \text { Oct. } 1991\end{array}$ & Campaign $^{3}$ & $\begin{array}{l}\text { (Posttest) } \\
\text { 20-31 Jan. } 1992\end{array}$ & Analysis \\
\hline Panel group & $N=747$ & $x$ & $N=548$ & $\begin{array}{l}\text { 'directly informed }(n=87) \\
\text { 'indirectly informed' } \\
(n=156) \\
\text { 'non-informed' }(n=305)\end{array}$ \\
\hline Measurement-control group & - & $x$ & $N=550$ & \\
\hline
\end{tabular}

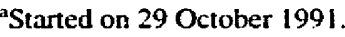

design and the numbers of subjects in the ultimate research groups are presented in Table 1.

\section{Research variables}

It would take too much space to describe all the variables used in this study and their measurement extensively. At the second measurement 51 questions were asked. So we will present only the most central variables in this section.

The following types of variables are used in the study: experimental variables (exposure to the campaign ), dependent variables (by means of which possible effects of the campaign are measured), and independent variables such as socio-demographic characteristics (potential disturbing factors). Obviously, the variable "exposure to the campaign" could be measured in the posttest only. In the panel group the dependent variables are measured both in the pretest and in the posttest, while the independent variables are measured in the pretest only. All variables regarding the measurement-control group are measured in the posttest only.

In order to establish the effects of the campaign, three different categories of respondents were defined:

(1) With regard to the first category, we distinguished the employees who had seen the posters, and/or the leaflets, and/or the booklets, from those who so far had remained ignorant of any information about working with carcinogens. From now on we will call the first mentioned group the "directly informed". It should be remarked that some members of this group were also aware of the campaign's subject through other sources, and/or by interpersonal communication.

(2) Secondly, we distinguished those workers whose knowledge had been acquired solely through other media, and/or by interpersonal communication (and thus not by means of the campaigns materials) from those who were totally ignorant. Henceforth we will call these respondents the "indirectly informed".

(3) Finally, the employees who were left unimpressed by the campaign at all are called the "non-informed".

The dependent variables refer to knowledge and awareness of (potential) carcinogenic substances in the work environment, knowledge and awareness of the dangers and risks of 
working with such substances, and knowledge of the law. Employers whose industries handle toxic and/or carcinogenic substances are obliged by law to register all these substances and to act according to statutory regulations with regard to safety measures.

Knowledge and awareness of (potential) carcinogenic substances in one's own working place were measured by asking the respondents whether they were sure or suspect that they were working with substances which might cause cancer. In addition, they were asked which substances were involved. The replies to this open question were encoded by a fellowworker of the section Toxic Substances of the Ministry of Labour and Social Affairs ${ }^{2}$ to classify the substances mentioned as (potentially) carcinogenic or not. In this way two variables could be identified: number of substances mentioned and which are, according to him, carcinogens (additive interval scale) and number of "correct" substances mentioned (additive interval scale). They were also asked to estimate their chances to get cancer as a result of working with possible carcinogens ( resulting in an ordinal scale: none, little, much, considerable). Also, their awareness of safety regulations was measured (dichotomous ordinal scale).

Some attitude variables were measured too, such as the "attitude towards safety regulations", "satisfaction with safety precautions and regulations in the own working environment"' and the "attitude towards the risks of working with carcinogenic substances"'. The last mentioned variable is operationalized by means of eight statements (additive Likert scale). The "(irrational) fear of carcinogenic substances" is also measured, in order to establish whether the campaign has possibly led to an increase of (irrational) fear of carcinogenic agents: a possible non-intended co-effect. This variable is operationalized by seven statements (additive Likert scale). The measurement level of all the attitudinal variables is at least ordinal.

Both the intention to behave in a preventive way and the asserted preventive behaviour itself regarding work with carcinogenic substances have also been measured. Among other things the respondents were asked whether they intend to comply with (extra) measures to reduce the risks attached to work with carcinogens, to what extent they act upon safety regulations and which activities they undertake of their own accord to reduce potential risks. These questions were open-ended. The answers were coded in two ways: first, is one willing to use some particular protective measure or device, or not (dichotomous ordinal variables). Second, by adding the protective activities mentioned (additive interval scale). It should be stressed that behaviour has not been observed directly, and consequenily has to be interpreted as "reported behaviour". This holds for the rest of this article.

In addition, some variables regarding interpersonal communication with regard to working with carcinogens were measured. The respondents were asked about the frequency of communication (never, sometimes, often) on the subject of the risks of working with carcinogenic substances with their colleagues, their management, their occupational health officer, with other physicians and with others. This gives five variables of an at least ordinal measurement level. They were also asked whether they had the intention to ask someone for information (yes or no) and if so, to whom they would direct themselves (open-ended). The answers to the last question were coded in two ways: a particular source (management,

${ }^{2}$ We are very grateful to Dr P. Kerklaan, who placed his knowledge and experience at our disposal to assist in the coding of respondents" professions and the substances they work with. 
colleague, occupational health officer, etc.) is mentioned or not (dichotomous variables) and the number of sources mentioned (additive interval scale).

In order to establish the effects of the campaign as accurately as possible, some potentially disturbing factors were included, e.g., sex, age, education, civil status, number of people and own position in the household, degree of urbanisation and region, size of the company, harm avoidance (operationalized by four statements), and one's concern about one's own health (operationalized by eight statements).

\section{Methods of analysis and testing}

Regarding the non-dichotomous or categorical dependent variables, the effects of the campaign on knowledge, attitude, behavioural intention and communication were determined by means of covariance analysis. In the case of dichotomous or categorical dependent variables, the effects of the campaign were assessed by means of loglinear analysis. In both types of analysis "exposure to the campaign" is used as an independent variable while "knowledge", "attitude", "behavioural intention" and "interpersonal communication" are treated as dependent variables. Those disturbing factors, which appeared to correlate significantly with "campaign-exposure" are introduced in the analyses as covariates in order to control them.

Consecutively two different analyses were executed: firstly, the "directly informed" employees are compared with the "non-informed" employees, and, secondly, the "indirectly informed" ones are compared with the "non-informed" ones. It appeared that the variables "directly informed" and "indirectly informed" did not correlate with exactly the same set of disturbing variables. Therefore, different disturbing variables were applied as covariates in the separate analyses. With regard to "directly informed" we used education, size of the industrial plant and the factor "harm avoidance" as covariates; with regard to "indirectly informed" education and household size. The pretest scores with regard to the dependent variables were also included as covariates in order to eliminate their possibly disturbing influence on the relationships under study. Because a positive effect of exposure to the campaign on the dependent variables was expected, all associations were tested onesided.

In order to establish the effect of exposure to the canipaign more accurately, potential measurement $e^{r c}$ zcts were also controlled in the analysis. The occurrence of measurement effects itself does not have to be problematic as long as these effects are distributed equally among the informed and non-informed respondents. If the informed employees, however, should have been influenced by the pretest in a way that the non-informed were not, then the results found would have to be ascribed - at least partially - to differential learning effects. However, during control we found no such differential learning effects to occur at all.

\subsection{Panel drop-out}

It appeared that $199(27 \%)$ respondents of the panel dropped out at the posttest. If dropouts should differ significantly from the remaining respondents regarding relevant dependent 
and independent variables, the external validity of the panel would be damaged. Comparison of relevant variables of those who dropped out with that of those of the remainder made it clear that there was a selective drop-out in the panel; significant differences were found in a small number of variables. Summarized, it appeared that the drop-outs considered working with carcinogenic substances not as dangerous as the remaining group did. The drop-outs were also somewhat more indifferent to the risks they run at work and with regard to environmental risks.

While comparing the panel with the measurement-control group we investigated to which extent one may still speak of a representative panel. First, we checked whether there were differences between the panel group in the pretest and the measurement-control group regarding the independent variables, to determine whether both research groups may be considered as representative for the same population. Only one significant difference came to light. The panel group agreed significantly less with the statement that "I never dwell on the idea that something could be bad for my health" (average score 2.36 versus 2.48: $T(1295)=-2.32, p<0.05)$. Next we compared the scores of the remainder of the panel at the posttest with those of the measurement-control group. No extra significant differences were found other than those revealed by comparing the total panel group with the measurement-control group. A significant difference showed up regarding the same statement as above (average score 2.34 versus 2.48: $T(1096)=2.40, p<0.05$ ). Therefore, we may conclude that the selective effect due to drop-out was limited, and that the damage to the panel was thus also negligible.

\section{Results}

\subsection{Reach and opinion}

Before the start of the campaign no clear goals were formulated regarding the percentage of the target group that had to be reached by the various campaign instruments. Therefore, it was difficult to judge if the reach of the campaign in the first three months would be wide enough. The results showed that $16 \%$ of the panel were acquainted with one or more of the campaign materials. A group of $28 \%$ were not aware of the campaign itself at all, but had received information about working with carcinogenic substances through other media or through interpersonal communication. More than half of the respondents (56\%) said that they had remained out of touch with "Work wisely" altogether.

Of all campaign materials the reach of the poster was the widest (seen by $13 \%$ of the panel group), followed by the leaflet (seen by $3 \%$ ) and finally by the booklet ( $1 \%$ ). Only $1 \%$ saw more than one campaign instrument. The majority of those who saw the leaflet had also read at least a few lines of it $(67 \%)$.

The respondents who saw one or more of the campaign materials were asked for their judgement. The opinions about the poster, leaflet, and the campaign as a whole were generally positive. Because only a few respondents had seen the pamphlet, hardly any significance can be attached to their positive opinion about this campaign instrument. It appeared that the poster did not urge the majority of those who saw it, to think about the risks of working with carcinogenic substances. By contrast, most of the subjects who saw 
the leaflet, said that it set them thinking about these risks. Probably, more information is needed than such as can be supplied by a poster, to make the message fully understood. An almost similar proportion of those who saw these materials, said that they acted with more care to reduce the risks of working with carcinogenic substances as a consequence of seeing the poster $(16 \%)$ or the leaflet $(17 \%)$.

With regard to interpersonal communication it appeared that $5 \%$ of the panel group had heard about the campaign from others, while $8 \%$ told others about the campaign. We found that significantly more respondents of the panel told others about it than those of the

Table 2

The effects of "direct" campaign exposure on knowledge, attitude, behavioural intention and communication". Results of the analysis of covariance. Only significant effects are presented

Dependent variables $\quad \frac{\text { Mean at } T 1^{\mathrm{b}}}{\text { not inf. inf. }}$

Knowledge variables

Number of substances mentioned with which the respondent works and which are. according to him, possible carcinogens

$n=302^{\mathrm{u}} \quad n=87 \quad 5.22$

0.023

$0.75 \quad 0.98$

Number of "correct" substances mentioned ( substances which are indeed

$n=302 \quad n=87 \quad 9.22$

0.003 possible carcinogens)

$0.30 \quad 0.51$

Estimation of the chance to get cancer $(1=$ none, $2=$ little. $3=$ much.

$n=257 \quad n=78 \quad 4.47$

$4=$ considerable)

$1.75 \quad 1.91$

\section{Attitude variables}

"All those safety regulations make working less pleasant" ${ }^{\circ "}(1=$ totally disagree, $2=$ disagree. $3=$ neutral, $4=$ agree, $5=$ totally agree)

$\begin{array}{lll}n=80 & n=40 & 3.63 \\ 3.47 & 3.11 \\ n=302 & n=87 & 3.20 \\ 1.78 & 1.64\end{array}$

"I think safety prescriptions for working with carcinogenic substances are superfluous" (idem)

\section{Behaviour variables}

Number of activities mentioned as undertaken to limit risk

$$
\begin{array}{lll}
n=302 & n=87 & 5.11 \\
0.68 & 0.99 &
\end{array}
$$

\section{Communication variables}

Talks about risks with the management $(1=$ never, $2=$ sometimes, $3=$ often $)$

$$
\begin{array}{lll}
n=280 & n=82 & 4.17 \\
1.54 & 1.68 & \\
n=247 & n=73 & 4.16 \\
1.13 & 1.23 & \\
n=302 & n=87 & 3.93 \\
0.32 & 0.45 &
\end{array}
$$

Number of persons mentioned to whom one intends to ask for information

\footnotetext{
"not inf. = not informed at all, inf. = informed by the campaign materials (and in addition possibly also by information from other media and/or through interpersonal communication).

'The differences between both groups at $T_{0}$ are being held constant by taking the pretest scores and potentially confounding factors (education. size of the industrial plant and the factor "harm avoidance") as covariates in the antlysis.

'In one-sided tests $p$-values $<0.10$, assessed by two-sided tests, are significant by alpha $=0.05$.

' $n$ (directly informed) $=87, n$ (not informed) $=305$. Due to missing values $n$ 's may be lower then 87 (directly informed) or 305 (not informed).

" $n$ is extra low because only those who admit that they have to work under safety conditions were asked to answer this question.
} 
measurement-control group. Probably this difference was brought about by the participation of the panel in the pretest.

\subsection{Effects of the campaign}

In order to establish the impact of the campaign on the panel group, we began by comparing those who saw one or more of the campaign materials (16\%: "directly" informed), with those who were still unfamiliar with any information about working with carcinogenic agents $(56 \%)$. In view of extensive free publicity about working with carcinogenic substances (for example in T.V. news-bulletins and in many newspapers), we also checked if there were any effects as a result of information about working with carcinogenic substances through other media and/or through interpersonal communication. Thus, we compared the answers of those who were "indirectly" informed $(28 \%)$ with the answers of those who were totally uninformed. By comparing the results of both types of information exposure, we may get an impression of the influence of the "extra" information about the subject spread through free publicity. Tables 2-5 show which dependent variables were changed significantly using the "directly informed" variable (Table 2 and Table 3) and the "indirectly informed" variable (Table 4 and Table 5), respectively.

From $t^{\prime} \geq$ results of being "directly informed" it can be concluded that the campaign materials were rather effective. It appeared in the posttest that the "directly" (i.e., by the campaign materials) informed employees as distinct from the non-informed ones:

Table 3

The effects of "direct" campaign exposure on knowledge, attitude, behavioural intention and communication". Results of the loglinear analysis. Only significant effects are presented

Dependent variables

$\mathrm{La}^{\mathrm{a}} \quad \mathrm{Chi}^{2 \mathrm{~b}}$ df $p<\mathrm{CC}^{\mathrm{c}} \quad N^{\mathrm{d}}$

Knowledge variables

Being certain of or suspecting to work with carcinogenic substances

( $1=$ does not work with it. $2=$ works certainly/likely with it)

Presence of safety regulations $(1=$ not present, 2 = present $)$

$\begin{array}{llllll}0.20 & 9.40 \quad 1 & 0.001 & 0.026 & 381\end{array}$

Behaviour variables

Use of protective clothing $(0=$ not mentioned, $1=$ mentioned $)$

Avoidance of direct contact with the substances (idem)

Communication variables

Has the intention to turn to the management for information $(0=$ not mentioned, $\mathrm{I}$ = mentioned)

$\begin{array}{llllll}0.26 & 5.52 & 1 & 0.025 & 0.049 & 335\end{array}$

$\begin{array}{llllll}0.12 & 2.93 & 0.10 & 0.060 & 389\end{array}$

$\begin{array}{llllll}0.29 & 7.83 & 1 & 0.01 & 0.024 & 389\end{array}$

$\begin{array}{lllllll}0.15 & 3.43 & 1 & 0.10 & 0.009 & 392\end{array}$

"Lambda: the parameter of the effect of "direct campaign exposure" on the dependent variables, controlling for pretest scores and other potentially confounding factors (education, size of the industrial plant and the factor "harm avoidance").

'Loglikelihood Chi-square, indicating the extent of improvement of the fit of the loglinear model if the independent variable "direct campaign exposure" is added to the model. If the value is significant ( $p, 0.10)$, it means that campaign exposure has a significant effect on the dependent variable.

'The Coefficient of Concentration (CC) indicates the extent (percentage) of the variance in the dependent variable explained by "direct exposure to the campaign".

${ }^{d} n$ (directly informed) $=87, n$ (not informed $)=305 . N($ total $)$ for this analysis: $87+305=392$. Due to missing values $N$ may be lower then 392 . 
Table 4

The effects of "indirect" campaign exposure on knowledge, attil :de, behavioural intention and communication". Results of the analysis of covariance. Only significant effects are

Dependent variables $\frac{\text { mean at } t 1^{\mathrm{b}}}{\text { not inf. inf. }}$

Knouledge variables

Number of substances mentioned (substances with which the respondent works and which are, according to him, possible carcinogens)

$\begin{array}{llll}n=305^{\mathrm{d}} & n=156 & 7.81 & 0.005 \\ 0.77 & 1.01 & & \\ & & & \\ n=305 & n=156 & 16.72 & 0.000 \\ 0.30 & 0.53 & & \end{array}$

Number of "correct" substances mentioned (substances which are indeed possible carcinogens)

$0.30 \quad 0.53$

\section{Behaviour variables}

Number of activities mentioned as undertaken to limit risk

$\begin{array}{llll}n=305 & n=156 & 7.95 & 0.005 \\ 0.70 & 1.05 & & \\ & & & \\ n=296 & n=153 & 3.43 & 0.065 \\ 1.76 & 1.86 & & \\ n=297 & n=154 & 10.51 & 0.001 \\ 1.51 & 1.69 & & \\ & & & \\ n=305 & n=156 & 6.71 & 0.010 \\ 0.32 & 0.47 & & \end{array}$

\section{Communication variables}

Talks about risks with colleagues $(1=$ never. $2=$ sometimes, $3=$ often )

Talks about risks with others (idem)

Has the intention to turn to others for information (idem)

Number of persons mentioned to whom one intends to ask for information

$0.32 \quad 0.47$

anot inf. = not informed at all, inf. $=$ informed only indirectly by information from other media and/or through interpersonal communication.

The differences between both groups ai $T_{0}$ are being held constant by taking the pretest scores and potentially confounding factors (education and household size) as covariates in the analysis.

'In one-sided tests $p$-values $<0.10$, assessed by two-sided tests. are significant by alpha $=0.05$.

${ }^{4} n$ (indirectly informed) $=156, n$ (not informed) $=3 i 5$. Due to missing values $n$ 's may be lower then 156 (indi. rectly informed) or 305 (not informed).

(1) answered more eften that they suspected or knew for sure that they were working with carcinogenic substances;

(2) possessed more knowledge at out the substances they worked with: on average the "directly informed" employees wer able to name a larger number of substances they work with and which they suspect of being carcinogenic. On average they mentioned more substances "correctly" (i.e., substances actually or probably carcinogenic).

(3) estimated their chances of getting cancer through working with carcinogenic substances somewhat higher;

(4) stated more frequently that there are safety regulations at their places of employment;

(5) agreed to a lesser extent with the statement that "all those safety prescriptions make working less pleasant" (this applies only to those who admit that they have to work under such safety conditions);

(6) agreed to a lesser extent with the statement that "safety prescriptions for working with carcinogenic substances are superfluous";

(7) more often said to exhibit protective bcha jiour: on average more "directly" informed employees said that they used protective clothing and told that they avoided direct contact 
Table 5

The effects of "indirect" campaign exposure on knowledge, attitude, behavioural intention and communication'. Results of the loglinear analysis. Only significant effects are presented

Dependent variables

$\mathrm{La}^{\mathrm{a}} \mathrm{Chi}^{2 \mathrm{~b}}$ df $\mathrm{p}<\mathrm{CC} \mathrm{CC}^{\mathrm{d}}$

Knowledge variables

Being certain of or suspecting to work with carcinogenic substances

$\begin{array}{lllll}0.12 & 4.11 & 1 & 0.05 & 0.024\end{array}$

451

( 1 = does not work with it, 2 = works certainly/likely with it)

Behaviour variables

Use of protective clothing ( $0=$ not mentioned, $I=$ mentioned $)$

Avoidance of direct contact with the substances (idem)

$\begin{array}{llllll}0.12 & 4.53 & 1 & 0.05 & 0.020 & 461\end{array}$

Does not smoke, drink and eat near the substances (idem)

$\begin{array}{llllll}0.23 & 9.24 & 1 & 0.005 & 0.029 & 461\end{array}$

Does not come or stay unnecessarily near the substances (idem)

$\begin{array}{lllllll}0.21 & 3.68 & 1 & 0.10 & 0.0129 & 461\end{array}$

Communication variables

$\begin{array}{llllll}0.22 & 5.08 & 1 & 0.025 & 0.011 & 461\end{array}$

$\begin{array}{lllllll}\text { Would turn to the company doctor with complaints }(0=\text { not mentioned, } & 0.14 & 4.71 & 1 & 0.05 & 0.013 & 461\end{array}$

I = mentioned)

Has the iniention to ask someone for information ( $1=$ no, $2=$ yes)

Has the intention to ask information from the Dutch Cancer Society

Information Centre (idem)

Has the intention to turn to others for information (idem)

$\begin{array}{llllll}0.13 & 3.87 & 1 & 0.05 & 0.016 & 332\end{array}$

$\begin{array}{lllllll}0.38 & 3.13 & 1 & 0.10 & 0.042 & 461\end{array}$

$\begin{array}{llllll}0.23 & 6.96 & 1 & 0.01 & 0.045 & 461\end{array}$

"Lambda: the parameter of the effect of "indirect campaign exposure" on the dependent variables. ccntrolling for pretest scores and other potentially confounding factors (education and household size).

"Loglikelihood Chi-square, indicating the extent of improvement of the fit of the loglinear model if the independent variable "direct campaign exposure" is added to the model. If the value is significant $(p<0.10)$, it means that campaign exposure has a significant effect on the dependent variable.

'The Coefficient of Concentration (CC) indicates the extent (percentage) of the variance in the dependent variable explained by "direct exposure to the campaign".

${ }^{n} n$ (indirectly informed) $=156, n$ (not informed $)=305 . N($ total $)$ for this analysis: $156+305=461$. Due to missing values $N$ may be lower then 461 .

with the substances. They also mentioned more participation in activities undertaken to limit risks;

(8) discussed the risks of working with carcinogenic substances with their management and occupational health officer more frequently;

(9) were more willing to approach others for information about working with carcinogenic substances. They mentioned a larger number of persons on average whom they intended to sound out on this matter.

When comparing the results of the îrst two tables with the next two, it appeared that most of the findings for the group of the "directly informed" workers also emerged in the "indirectly informed" group. Nearly all findings in the knowledge variables for "direct" information to the campaign were also observed for "indirect" information, with the exception of the effects on the variables "estimation of the chance to get cancer" and "presence of safety regulations" which were manifest in "directly informed" only. Concerning the "indirectly" informed employees, effects on two more behaviour variables could be shown: "do not smoke, drink and eat anywhere near the substances" and "do not come or stay unnecessarily close to the substances", which were absent in the results for the "directly informed". In the attitude variables we found effects as a consequence of "direct" information only. Regarding the effects on the variables for interpersonal com- 
munication about working with carcinogenic substances, several differences were found. A striking difference is the one regarding the variable "talk about risks with the management". As expected, only directly informed employees talked more about risks with their management than non-informed employees. This was to be expected because it was an explicit advice given in the campaign materials but not reported in the free publicity content.

\section{Discussion and conclusions}

In spite of the fact that there were no clear criteria set, on the basis of which we would be able to decide whether the reach of the campaign was either successful or not, we had to admit that the reach of the campaign "Work wisely" was very limited. In particular the booklet was noticed by a few respondents only. However, especially in view of the full effect of the campaign (including free publicity) on (reported) behaviour variables we may speak of a successful action which has been reasonably effective. In view of the aims of the campaign (providing information about and calling attention to safer handling of carcinogenic substances, in order to take the first step in the direction to the propagated behaviour), and to promote interpersonal communication with the persons involved, expectations to achieve actual behavioural change were not high anyway. This seems a realistic view as it appears from numerous studies in the field of health education that mass media have a strong impact with regard to calling attention to certain affairs and the increase of knowledge, but have hardly any influence regarding a change in attitudes and actuai behaviour (Klapper, 1960; Atkin, 1979; Wallack, 1981). However, the impact of mass media campaigns is generally much stronger when their messages can generate interpersonal communication on the issues involved (See among others Richman and Urban, 1978; Van der Rijt, 1979; Alcalay, 1983; Rogers, 1983; Van der Rijt and Baan, 1984; Flay, 1987).

In this study, effects of the campaign were clearly discernible in quite a number of variables regarding knowledge, communication and (intentional) behaviour. Apparently the campaign enlarged knowledge of the risks of occupational exposure to carcinogenic substances, and stimulated communication on this subject. This interpersonal communication might have contributed to the change in (intentional) behaviour. However, "Work wisely" does not appear to have had much effect on the attitude variables. This could mean that the desired attitude towards working with carcinogenic substances did already largely exist before the start of the campaign. This supposition may clear up why the campaign can have led to the behavioural change found. It also seems plausible that the behaviour propagated by the campaign (protecting oneself when working with carcinogenic substances) is easier to achieve than most other behavioural changes which one tries to promote through health information campaigns (e.g., non-smoking, the use of healthier food, reducing alcohol consumption). Not applying protective precautions during work with carcinogens is not such a deep-seated personal habit as for example smoking and drinking habits. Another possible explanation for the occurrence of behavioural change is the fact that the campaign materials gave concrete examples of what to do in order to reduce the risks of working with carcinogenic substances. From previous studies of the effects of media campaigns on the prevention of cancer, it appears that a message holding concrete instructions of how to realize preventive behaviour will probably be more effective than a campaign message 
lacking such instructions (Leventhal et al., 1983; Seydel, 1989). Finally, we have to stress that behaviour changes are not assessed by observation, but by means of self-reports of the respondents. Biased reporting could offer a third explanation for the behaviour effects found. So we have to interpret these findings with caution.

It was found that exposure to "direct" information about working with carcinogenic substances produced partly the same effects as and partly some other than in the case of "indirect" exposure. However, a pure comparison between "direct" and "indirect" exposure to the campaign is not really possible because some of those being informed by the campaign materials were also instructed by other media and/or through interpersonal communication. From the results submitted in this article the conclusion can be drawn that information through other media (than the campaign itself), and/or through interpersonal communication is fairly effective. Besides the fact that many of the effects found for "direct" exposure to the campaign were also found for "indirect" exposure, there were also effects applicable to "indirect" exposure only. Consequently, there is no denying that exposure to information about working with carcinogenic substances through outside media, resulting in interpersonal communication about the campaign's subject, must have a clear impact. This underlines the importance of supportive free publicity for a campaign like this. It has, therefore, to be strongly recommended to mobilise further support for "Work wisely" and for any future campaigns from free publicity.

On the basis of the results discussed above it can be concluded that it makes sense to continue the "Work wisely" campaign. The finding that knowledge about the substances which employees work with has increased and that interpersonal communication about the subject occurred, shows a lot of interest in and susceptibility for information about working with carcinogenic substances in the target group. An important result of this study is also that there are no indications that the campaign has led to an increase of (irrational) fear of carcinogenic sabstances. This should dispel any idea that better information of workers about work-related risks might have a boomerang effect. Therefore it is of utmost importance to strive for a wider reach of the campaign materials in the target group. Distribution through libraries was found to be successful, although it has only a limited reach in the target group. Unfortunately, it appeared that only a few occupational health officers cooperated in the campaign so far. Further research should answer the questions of how to mobilise and motivate these groups of intermediaries, and to decide which additional intermediaries should be approached for extra support to the campaign.

Obviously, the question remains how far the effects established after three months of campaigning will last in the long run. However, given the interpersonal communication stimulated by the campaign, "Work wisely" will probably prove to be even more effective in the time to come.

\section{References}

Alcalay, R., 1983. The impact of mass communication campaigns in the health field. Soc. Science Medicine, 17: 87-94.

Atkin, Ch.K., 1979. Research evidence on mass mediated health conmunication campaigns. in: D. Nimmo (Ed.), Communication Yearbook 3 (Transaction, New Brunswick. New Yersey) pp. 655-668.

Flay, B., 1987. Mass media and smoking cessation: A critical review. Am. J. Public Health, 77: 153-160. 
Klapper, J.T., 1960. Effects of Mass Communication, Glencoe.

Leventhal, H., Safer, M.A. and Panagis, D.M., 1983. The impact of communications on the self-regulation of health beliefs, decisions and behavior. Health Education Quarterly, 10: 3-29.

McGuire, W., 1981. In: R. Rice and W. Paisley (Eds.), Theoretical Foundations of Campaigns (Public Communication Campaigns).

Richman, L. and Urban, D., 1978. Health education through television: some theoretical applications. Int. J. Health Education, 21: 46-52.

Rijt, G.A.J. van der, 1979 Adolescence and anti-smoking information (Jeugd en anti-rookinformatie). Thesis, ITS, Nijmegen.

Rijt. G.A.J. van der and Bain. 3., 1984. Mass communication, the prelude to interpersonal communication: the effective way to convince. Tijdschrift voor alcohol en drugs, 10: 9-18.

Rogers, E.M., 1983. The Diffusion of Innovations (Free Press, NY).

Seydel. E.. [989. Cancer and the general public. Experimental health education (Kanker en het algemene publiek. Experimenten met kankervoorlichting). Thesis, University of Twente, Enschede.

Wallack. L.M. 1981. Mass media campaigns: the odds against finding behavior change. Health Education Quarterly. 8: 56-89. 